\title{
Inheritance of Elastic and Viscoelastic Components of Tomato Firmness Derived from Intra- and Interspecific Genetic Backgrounds
}

\author{
John R. Stommel ${ }^{1}$ \\ U.S. Department of Agriculture, Agricultural Research Service, Beltsville Agricultural Research Center, \\ Plant Sciences Institute, Vegetable Laboratory, 10300 Baltimore Avenue, Beltsville, MD 20705
}

Judith A. Abbott

U.S. Department of Agriculture, Agricultural Research Service, Beltsville Agricultural Research Center, Plant Sciences Institute, Produce Quality and Safety Laboratory, 10300 Baltimore Avenue, Beltsville, MD 20705

\author{
T. Austin Campbell \\ U.S. Department of Agriculture, Agricultural Research Service, Beltsville Agricultural Research Center, \\ Plant Sciences Institute, Soybean Genomics and Improvement Laboratory, 10300 Baltimore Avenue, \\ Beltsville, MD 20705 \\ David Francis \\ Department of Horticulture and Crop Science, Ohio State University, OARDC, 1680 Madison Avenue, \\ Wooster, $\mathrm{OH} 44691$
}

\begin{abstract}
AdDITIONAL INDEX WORDs. diallel, fruit quality, Lycopersicon esculentum, Lycopersicon cheesmanii, puncture resistance, combining ability

Abstract. Fruit firmness is a key quality component of tomatoes (Lycopersicon esculentum Mill.) for fresh-market and processed product applications. We characterized inheritance of firmness in processing tomato germplasm developed from interspecific L. esculentum Mill. x L. cheesmanii f. minor (Hook. f.) C.H. Mull. and intraspecific L. esculentum crosses. Although firmness is a key quality attribute of tomato, there is no standard method for measuring it. We measured the elastic portion of firmness by compression (compression $F_{\text {max }}$ ) and puncture (puncture $F_{\text {max }}$ ), and the viscoelastic portion by force-relaxation. The experimental design incorporated six genotypes in a complete $6 \times 6$ diallel. Compression $F_{\text {max }}$ and force measurements recorded at $0.5,1.0,5.0$, and 10.0 seconds of relaxation were strongly related to each other, while relaxation parameters $(\mathrm{A}, \mathrm{B}, \mathrm{C})$ describing relaxation curve shape were generally independent. Compression $F_{\max }$, relaxation curve parameter $A$, and puncture $\mathbf{F}_{\max }$ were significantly different among hybrids. Significant differences between Maryland and Ohio environments were evident for compression $F_{\text {max }}$ and relaxation curve parameter A. The patterns of firmness means differed among firmness measurement methods, namely for compression $\mathbf{F}_{\max }$ and puncture $\mathbf{F}_{\max }$, indicating that they measure different aspects of tomato fruit firmness. Soft-fruited parents generally exerted a negative effect on compression $F_{\max }$, whereas firm-fruited parents most often exerted a positive effect on compression $F_{\max }$. The force required for fruit compression best approximated subjective assessment of fruit firmness. Force required for fruit puncture was subject to a significant environmental $\times$ hybrid influence in the genotypes evaluated. Shape of the force relaxation curve (i.e., parameter A) was not predictive of relative fruit firmness. General combining ability (GCA) and specific combining ability were both significant with GCA being the principal source of genetic variation. In agreement with combining ability estimates, narrow-sense heritability estimates for compression $\mathbf{F}_{\max }$ and puncture $\mathbf{F}_{\max }$ were relatively high.
\end{abstract}

Firmness is a key quality component of tomatoes grown for fresh-market and processing applications. Marketing of fresh tomato fruit has necessitated development of cultivars with enhanced fruit firmness to withstand the rigors of long-distance shipping. The development of determinate cultivars with a concentrated set of firm fruit has been critical to the success of mechanically harvested tomatoes for use in processed products.

Received for publication 20 Dec. 2004. Accepted for publication 27 Feb. 2005 We thank Andrea Blas, Mindy Ehrenfried, and Euhnee Park for valuable technical assistance and Matthew Kramer (Biometrical Consulting Service) and Kathleen Haynes for assistance with statistical analyses. Mention of trade names or commercial products in this article is solely for the purpose of providing scientific information and does not imply recommendation or endorsement by the U.S Dept. of Agriculture.

'To whom reprint requests should be addressed. Email address: stommelj@ba. ars.usda.gov
Considerable research has been conducted to identify key indices of tomato fruit softening. Stevens (1986) demonstrated that firm tomato fruits with thick walls and reduced locular area exhibit increased fruit alcohol insoluble solids and reduced sugar content relative to softer cultivars. Positive correlations between tomato fruit firmness and skin and flesh puncture resistance, and between fruit firmness and the amount of inner and outer wall were demonstrated (Kamimura et al., 1973). More recently, efforts to inhibit expression of cell wall degrading enzymes including polygalacturonases and pectinesterases in transgenic tomato plants have resulted in significant increases in viscosity and soluble solids and small changes in firmness (e.g., Kramer et al., 1992; Schuch, 1994). Similarly, expansin proteins that function in cell wall loosening were found to be abundant in the later stages of tomato fruit ripening with levels influenced by the ripening hormone ethylene (reviewed by Cosgrove, 2000). 
Although repression or overexpression of the expansin gene demonstrated that expansin functions in fruit softening, textural changes were relatively small, with fruit softening simply delayed or accelerated. In transgenic tomatoes with down-regulated $\beta$ galactosidase 4, whole fruit firmness was significantly greater relative to controls in four of six antisense lines, with one line being nearly $40 \%$ firmer (Smith et al., 2002). Clearly, multiple factors contribute to fruit softening.

Tomato fruit firmness is generally considered to be a quantitatively inherited trait (Al-Falluyi et al., 1982; Rau et al., 1994), although El-Sayed et al. (1966) reported the action of a single major gene with modifiers that influenced fruit firmness. Qualitative inheritance of firmness is also supported by Kuehn and Nichols (2003). With few exceptions, pericarp firmness of tomato cultivars was likely derived from a fairly narrow genetic background and was the result of the cumulative efforts of a number of breeders over many years (Stevens and Rick, 1986). Scott (1983) chronicled the origins of tomato fruit firmness in prevailing cultivars from major production areas of the world and concluded that genetic variation for tomato firmness was derived from a similar genetic background and may have originated from Lycopersicon pimpinellifolium (L.) Mill. In addition to quantitative genetic variation for tomato fruit firmness, a number of simply inherited ripening mutants including rin and nor (e.g., Aly, 1986; Elkind et al., 1990) have been described that influence fruit firmness, the degree of which is dependent on the genetic background in which the mutant genes are expressed.

Despite inferior phenotypes, wild species contain loci that may substantially increase tomato fruit quality (e.g., de Vicente and Tanksley 1993; Eshed and Zamir, 1994). We characterized inheritance of firmness in processing tomato germplasm developed from interspecific L. esculentum $\mathrm{x}$ L. cheesmanii and intraspecific L. esculentum crosses. Although firmness is a key quality attribute of tomato, there is no standard method for measuring it. Firmness encompasses elastic and viscoelastic properties. We measured the elastic portion of firmness by compression and puncture, and the viscoelastic portion by force-relaxation.

\section{Materials and Methods}

Plant material. Six tomato genotypes were selected for firmness evaluations based upon subjective field evaluation of fruit firmness and preliminary measurements of fruit compression and puncture resistance. The six genotypes selected produced commercial size fruit typically utilized for whole pack or diced product. Firm genotypes included one commercial processing tomato cultivar, Ohio 8245 developed from intraspecific L. esculentum crosses with no known prior L. cheesmanii introgressions (Berry and Gould, 1991), and three USDA breeding lines designated 01L648-8, 01L652-11, and 02L1370. Lines 01L648-8 and 01L652-11 were inbred lines derived from an interspecific cross between the wild tomato species $L$. cheesmanii (accession LA 317) and breeding lines containing no known sources of the wild species. Line 02L1370 was a firm-fruited breeding line developed from intraspecific L. esculentum crosses with no known prior L. cheesmanii introgressions. Two soft genotypes included in firmness evaluations were USDA breeding lines 99L115-4 and 00L161-12. Similar to 02L1370, these lines were developed from intraspecific L. esculentum crosses containing no known $L$. cheesmanii introgressions.

The experimental design was a randomized complete block arranged in a complete $6 \times 6$ diallel consistent with Griffing's
(Griffing, 1956) Method 1 where crosses, reciprocals, and selfs of parental lines are included. Plots included three replications in two locations. Six-week-old plants of each genotype grown in the greenhouse using standard production practices were transplanted to field plots at the Beltsville Agricultural Research Center, Beltsville, Md., and the Ohio State Univ., Ohio Agricultural Research and Development Center's Vegetable Crops Branch in Fremont, Ohio. Plants were spaced at 0.6-m intervals in single rows on raised beds, with beds positioned on 1.5-m centers. Pest control and fertilizer regimes followed standard horticultural practices for tomato production (Precheur, 2000; University of Maryland, $2000)$. Twenty ripe fruit of each lot (genotype $\times$ replicate $\times$ location) were harvested and measured for fruit firmness using fruit compression and puncture resistance. Fruit produced in Ohio were harvested, packed in single layers on molded pulp produce trays (three layers/carton) in cardboard shipping boxes and transported to Beltsville within $24 \mathrm{~h}$ for firmness evaluation.

Firmess evaluation. Compression force-deformation curves were recorded using a universal testing (force/deformation) instrument (Texture Analyzer TA-XTPlus; Stable Microsystems, Surrey, England). Intact fruit were supported with the stem axis horizontal and a locule in the uppermost position. Compression was measured with a flat plate $\approx 38 \mathrm{~mm}$ diameter, loading to $3 \mathrm{~mm}$ deformation at $3 \mathrm{~mm} \cdot \mathrm{s}^{-1}$ and then holding that deformation for 15 s to follow force relaxation (Fig. 1). Force at the end of the loading phase (i.e., at maximum deformation) is analyzed as compression $\mathrm{F}_{\text {max }}$, and forces at $0.5 \mathrm{~s}, 1.0 \mathrm{~s}, 5.0 \mathrm{~s}$, and $10.0 \mathrm{~s}$ relaxation were also extracted for evaluation. The relaxation portion of the curve was then standardized by dividing each force value by the force at time zero (i.e., expressing each as a percentage of the initial force value). The shape or curvature of the relaxation portion of the compression-relaxation curve was described by applying an empirical three-parameter (A, B, C) equation (Wu and Abbott, 2002) to the standardized curve. Figure 1 demonstrates the forces during loading and relaxation of a typical tomato and illustrates the effects of $\mathrm{A}, \mathrm{B}$, and $\mathrm{C}$ on the relaxation curve. $\mathrm{A}$ is related to overall viscoelasticity of the sample with larger valued samples being less viscous. Increases in the value of B shift the relaxation curve downward. Thus, the elastic fruit response tends to decrease as the value of $\mathrm{B}$ increases. The value of $\mathrm{C}$ affects the rate of change or sharpness of curvature in the initial seconds of relaxation. As a result, $\mathrm{C}$ is indicative of the quickness of relaxation, whereas A and B indicate the extent of relaxation. Due to the time required for the relaxation measurement on 4320 tomatoes, only two replicates from each location were measured for the relaxation variables; simple compression (compression $\mathrm{F}_{\max }$ ) was measured on the remaining replicate from each location.

Puncture tests were similarly made using the same instrument as for compression tests. Puncture tests were performed on all tomatoes (on a different locule than used for compression tests) using a 4-mm cylindrical probe driven $10 \mathrm{~mm}$ into the tomato. The maximum force (puncture $\mathrm{F}_{\max }$ ) required to penetrate the outer pericarp and the deformation at which puncture occurred were recorded.

Data were analyzed using DIALLEL-SAS3 (Zhang and Kang, 1997) to partition environment, GCA, specific combining ability (SCA), reciprocal effects, and individual effects. Narrow-sense heritability was estimated as

$\mathrm{h}^{2}=4 \sigma_{\mathrm{GCA}}^{2} /\left(\sigma_{\mathrm{e}}^{2} / \mathrm{r}+4 \sigma^{2} \mathrm{SCA}+4 \sigma_{\mathrm{GCA}}^{2}\right)$ where $\sigma_{\mathrm{e}}^{2}=$ error variance, $\sigma^{2}{ }_{\mathrm{GCA}}=\mathrm{GCA}$ variance, $\sigma^{2} \mathrm{SCA}=\mathrm{SCA}$ variance, and $\mathrm{r}=$ number of replications (Hallauer and Miranda, 1981). The standard error of $\mathrm{h}^{2}$ was estimated as $4 \mathrm{SE}\left(\sigma_{\mathrm{GCA}}^{2}\right) /\left(\sigma_{\mathrm{e}}^{2} / \mathrm{r}+4 \sigma_{\mathrm{SCA}}^{2}+4 \sigma_{\mathrm{GCA}}^{2}\right)$ where 


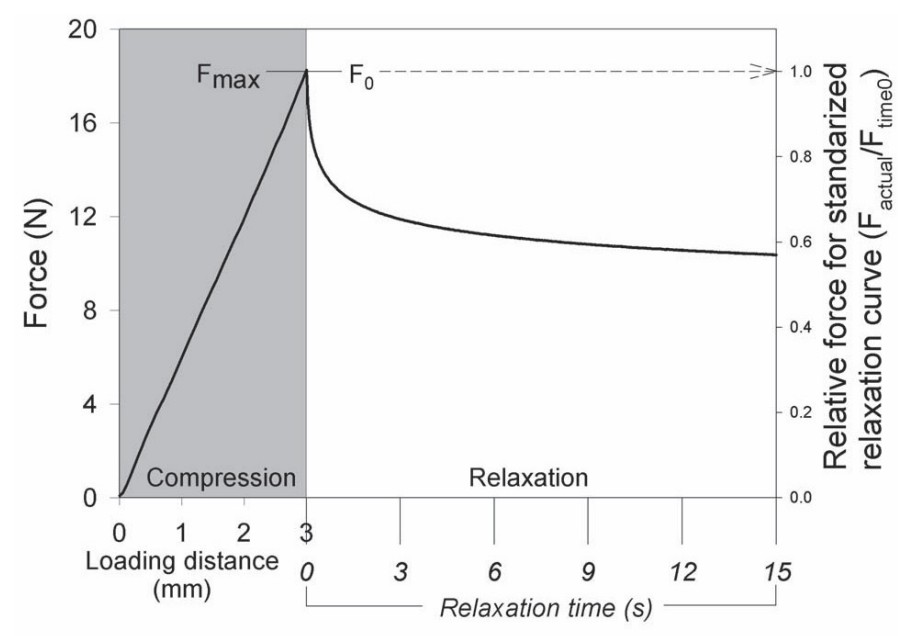

Relaxation curve-shape parameters

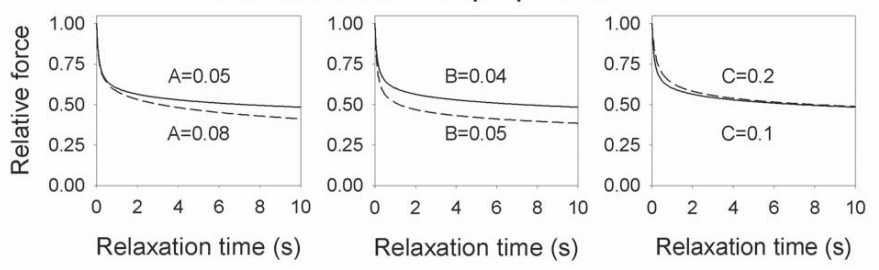

Fig. 1. Normalized force-relaxation curve for tomato and effects of increasing values for three relaxation curve parameters $\mathrm{A}, \mathrm{B}$, and $\mathrm{C}$ (normalized force $=$ force/initial force). Arrows point to increasing values. Adapted from $\mathrm{Wu}$ and Abbott (2002).

$\mathrm{SE}=$ standard error. The variance of $\sigma_{\mathrm{GCA}}^{2}$ was obtained as $2 /[\mathrm{r}(\mathrm{n}-2)]^{2}\left\{\mathrm{M}_{21}{ }^{2} /(\mathrm{n}+1)+\mathrm{M}_{22}{ }^{2} /[\mathrm{n}(\mathrm{n}-3) / 2]+2\right\}$ where $\mathrm{n}$ $=$ number of parents, $\mathrm{M}_{21}=$ GCA variance, and $\mathrm{M}_{22}=$ SCA variance (Hallauer and Miranda, 1981).

\section{Results and Discussion}

Tomato fruit firmness was evaluated by quantifying force required for fruit compression, force present at fixed intervals post compression (i.e., relaxation), and force required for fruit puncture. Compression (compression $\mathrm{F}_{\max }$ ) and relaxation force measurements $(0.5 \mathrm{~s}, 1.0 \mathrm{~s}, 5.0 \mathrm{~s}$, and $10.0 \mathrm{~s})$ across the parental lines and their hybrids were strongly related to each other while relaxation parameters $(\mathrm{A}, \mathrm{B}, \mathrm{C})$ describing relaxation curve shape were generally independent (Table 1). Compression $\mathrm{F}_{\max }$ and relaxation forces at $0.5 \mathrm{~s}, 1.0 \mathrm{~s}, 5.0 \mathrm{~s}$, and $10.0 \mathrm{~s}$ exhibited relatively large and significant coefficients of determination (Table 1). Conversely, $r^{2}$ values between $\mathrm{A}, \mathrm{B}$, and $\mathrm{C}$ were relatively low, with the exception of that between B and C. Although often significant, coefficients of determination describing the relationship between compression firmness and relaxation curve parameters $\mathrm{A}, \mathrm{B}$, and $\mathrm{C}$ were low (Table 1).

Therefore, fruit compression force-related measurements largely account for the elastic component of fruit firmness, while the relaxation curve parameters measured predominantly viscoelasticity or the viscous portions of fruit texture. These results are consistent with the results of Wu and Abbott (2002) who evaluated both intact fruit and fruit slices, noting close correlation between compression $\mathrm{F}_{\max }$ and force-related values from the compression and force-relaxation portions of the curve, but not with the three relaxation curve-shape parameters. Since compression $\mathrm{F}_{\max }$ was closely related to force at $0.5 \mathrm{~s}, 1.0 \mathrm{~s}, 5.0$ $\mathrm{s}$, and $10.0 \mathrm{~s}$ of relaxation, only compression $\mathrm{F}_{\max }$ was chosen for further discussion. Because the $\mathrm{B}$ and $\mathrm{C}$ relaxation curve parameters did not differ significantly among genotypes, they will not be further discussed.

Considerable variation in firmness was noted among parental genotypes and their progeny based upon instrument evaluation (Table 2, Fig. 2). Overall values for compression $F_{\max }$, relaxation curve parameter $\mathrm{A}$, and puncture $\mathrm{F}_{\max }$ were significantly different among hybrids (Table 3). Significant differences between Maryland and Ohio environments were evident for compression $\mathrm{F}_{\text {max }}$ and relaxation curve parameter $\mathrm{A}$, indicating that environment influenced fruit firmness. A significant environment $\times$ hybrid interaction was noted for compression $\mathrm{F}_{\max }$ and puncture $\mathrm{F}_{\max }$ denoting a differential response among hybrids for these parameters across the two production locations. The environment $\times$ hybrid interaction for compression $\mathrm{F}_{\max }$ was small, however, relative to the large environment effect.

In agreement with subjective firmness assessments, compression $\mathrm{F}_{\max }$ was greater in fruit of the firm parental genotypes 01L648-8, 02L1370, and Ohio 8245 in comparison to those subjectively rated as soft (99L115-4, 00L161-12) (Table 2). Contrary to subjective evaluations, fruit of 01L652-11 had the lowest compression $\mathrm{F}_{\max }$ value of the subjectively rated firm lines, and were not significantly different from lines rated soft. Although compression $\mathrm{F}_{\max }$ scores were lower for fruit produced in Ohio, trends were similar across locations. Relative to fruit of parental genotypes rated soft, the force required to puncture fruit pericarp (puncture $\mathrm{F}_{\max }$ ) was significantly greater in fruit of all firm rated genotypes (01L648-8, 01L652-11, 02L1370, Ohio 8245) produced in Maryland. Puncture $\mathrm{F}_{\max }$ exhibited little relationship with subjective firmness for fruit produced in Ohio. Considerable variability was evident for relaxation curve parameter A values (Table 2). A relationship between relaxation curve parameter A

Table 1. Coefficients of determination for force-relaxation curve parameters depicted in Fig. 1 [tomato fruit compression at maximum fruit deformation (Compression $\mathrm{F}_{\max }$ ), force at $0.5 \mathrm{~s}, 1.0 \mathrm{~s}, 5.0 \mathrm{~s}$, and $10.0 \mathrm{~s}$, and relaxation curve parameters A, B, and C].

\begin{tabular}{lccccccc}
\hline \multicolumn{2}{c}{ Compression $\mathrm{F}_{\max }$} & $0.5 \mathrm{~s}$ & $1.0 \mathrm{~s}$ & $5.0 \mathrm{~s}$ & $10.0 \mathrm{~s}$ & $\mathrm{~A}$ & $\mathrm{~B}$ \\
\hline Compression $\mathrm{F}_{\max }$ & 1.00 & & $\left(r^{2}\right)$ & & & & \\
$0.5 \mathrm{~s}$ & $0.46^{* * *}$ & 1.00 & & & & & \\
$1.0 \mathrm{~s}$ & $0.56^{* * *}$ & $0.99^{* * *}$ & 1.00 & & & & \\
$5.0 \mathrm{~s}$ & $0.70^{* * *}$ & $0.90^{* * *}$ & $0.96^{* * *}$ & 1.00 & & & \\
$10.0 \mathrm{~s}$ & $0.74^{* * *}$ & $0.87^{* * *}$ & $0.94^{* * *}$ & $1.00^{* * *}$ & 1.00 & & \\
$\mathrm{~A}$ & $0.20^{* * *}$ & $0.24^{* * *}$ & $0.30^{* * *}$ & $0.36^{* * *}$ & $0.37^{* * * *}$ & 1.00 & \\
$\mathrm{~B}$ & $0.03^{*}$ & $0.32^{* * *}$ & $0.23^{* * *}$ & $0.09^{* * *}$ & $0.07^{* *}$ & 0.01 & 1.00 \\
$\mathrm{C}$ & $0.15^{* * *}$ & $0.07^{* *}$ & 0.03 & 0.00 & 0.01 & $0.09^{* * * *}$ & $0.81^{* * *}$ \\
${ }^{*, * *, * * *}$ Significant at $P \leq 0.05,0.01$, and 0.001, respectively. & & &
\end{tabular}


Table 2. Parental genotypes, subjective firmness assessments, and mean firmness values for force at maximum fruit deformation (Compression $\mathrm{F}_{\max }$ ), relaxation curve parameter $\mathrm{A}$, and maximum force required for fruit puncture (Puncture $\mathrm{F}_{\max }$ ) in tomato fruit produced at Maryland (MD) and Ohio $(\mathrm{OH})$ test plots.

\begin{tabular}{|c|c|c|c|c|c|c|c|}
\hline \multirow[b]{2}{*}{ Genotype } & \multirow{2}{*}{$\begin{array}{c}\text { Firmness } \\
\text { assessment }\end{array}$} & \multicolumn{2}{|c|}{$\begin{array}{c}\text { Compression } \mathrm{F}_{\max } \\
{[\text { mean } \pm \mathrm{SE}(\mathrm{N})]}\end{array}$} & \multicolumn{2}{|c|}{$\begin{array}{l}\text { Relaxation curve parameter A } \\
{[\text { mean } \pm \mathrm{SE}(\times 1000)]}\end{array}$} & \multicolumn{2}{|c|}{$\begin{array}{c}\text { Puncture } F_{\max } \\
{[\text { mean } \pm \operatorname{SE}(N)]}\end{array}$} \\
\hline & & MD & $\mathrm{OH}$ & MD & $\mathrm{OH}$ & MD & $\mathrm{OH}$ \\
\hline 01L648-8 & Firm & $20.88 \pm 0.51$ & $16.90 \pm 0.55$ & $-5.23 \pm 2.69$ & $-6.85 \pm 3.25$ & $16.86 \pm 0.43$ & $13.81 \pm 0.53$ \\
\hline 01L652-11 & Firm & $17.23 \pm 1.55$ & $13.19 \pm 0.61$ & $-15.96 \pm 4.10$ & $-3.70 \pm 0.56$ & $14.95 \pm 0.63$ & $14.82 \pm 0.55$ \\
\hline 02L1370 & Firm & $22.35 \pm 2.59$ & $18.71 \pm 0.91$ & $-28.47 \pm 4.53$ & $-10.52 \pm 4.03$ & $14.29 \pm 0.99$ & $13.39 \pm 0.20$ \\
\hline Ohio 8245 & Firm & $19.51 \pm 1.41$ & $14.37 \pm 0.55$ & $-13.81 \pm 7.42$ & $-5.82 \pm 1.56$ & $13.22 \pm 0.31$ & $13.94 \pm 0.20$ \\
\hline 99L115-4 & Soft & $16.56 \pm 0.95$ & $11.81 \pm 0.60$ & $-18.63 \pm 0.33$ & $-1.96 \pm 1.48$ & $12.77 \pm 0.06$ & $14.48 \pm 0.86$ \\
\hline 00L161-12 & Soft & $16.78 \pm 0.19$ & $12.49 \pm 0.57$ & $-5.39 \pm 4.60$ & $-16.19 \pm 1.94$ & $12.74 \pm 0.24$ & $12.91 \pm 0.90$ \\
\hline
\end{tabular}

and firmness in soft and relatively firmer parental genotypes was not evident at either production location.

The patterns of firmness means differed among firmness measurement methods, namely for compression $\mathrm{F}_{\max }$ and puncture $\mathrm{F}_{\max }$, indicating that they measured different aspects of tomato fruit firmness, were inherited independently, and contributed

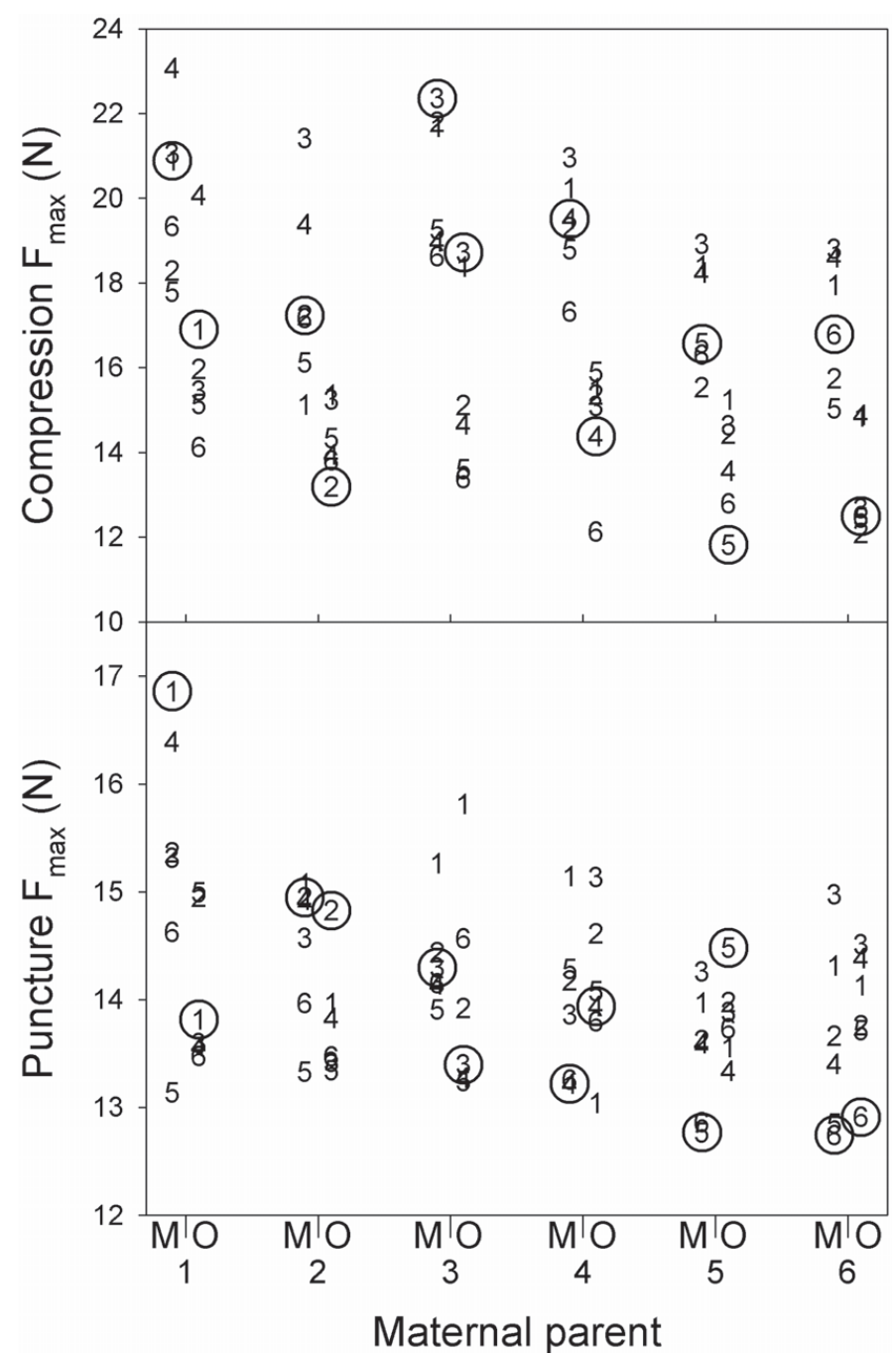

Fig. 2. Mean tomato fruit firmness of progeny by parental genotype. Force at maximum fruit deformation (Compression $\mathrm{F}_{\max }$ ) (upper panel) and maximum force required for fruit puncture (Puncture $\mathrm{F}_{\max }$ ) (lower panel) for hybrids evaluated for fruit firmness. Maternal parents are noted on the $\mathrm{x}$-axis; plotted numbers denote paternal parents; circled values are parental hybrids; $M$ and $\mathrm{O}$ (x-axis) denote Maryland and Ohio production locations, respectively. $1=$ 01L648-8; 2 = 01L652-11; 3 = 02L1370; 4 = Ohio 8245; 5 = 99L115-4; 6 = 00L161-12. differentially to firmness in the parental genotypes and their hybrids. Soft-fruited parents generally exerted a negative effect on compression $\mathrm{F}_{\max }$, whereas firm-fruited parents, with the notable exception of 01L652-11, exerted a positive effect on compression $\mathrm{F}_{\max }$ in crosses with lower valued genotypes (Table 4, Fig. 2). For the Maryland location, genotype 01L648-8 exhibited the greatest puncture $\mathrm{F}_{\max }$ score and had the most consistent positive effect on improving puncture ratings in crosses with other genotypes. The variation observed provided evidence of additive variation for the compression $\mathrm{F}_{\max }$ and puncture $\mathrm{F}_{\max }$ components of fruit firmness. These results demonstrate that measure of the force required for fruit compression best approximated subjective assessment of fruit firmness via hand feel. Compression force parameters measure the ability of fruit to withstand forces such as dropping and the weight of other fruit in a load while relaxation curve parameters measure the ability to recover shape after such forces. Force required for fruit puncture is a measure of fruit skin strength as well as the underlying tissue firmness and was subject to a significant environmental $\times$ hybrid influence in the genotypes evaluated. Although forces at $0.5 \mathrm{~s}, 1.0 \mathrm{~s}, 5.0 \mathrm{~s}$, and $10.0 \mathrm{~s}$ of relaxation were closely related to compression $\mathrm{F}_{\max }$, shape of the force relaxation curve (i.e., parameter A) was not predictive of fruit firmness. Environmental differences noted between production locations likely contributed to differences noted in firmness assessments. Above average precipitation was recorded in Maryland during the 2003 production season. Average monthly precipitation for the June to September period in Beltsville, Maryland was $73.2 \%$ greater than that recorded at the Ohio site. Although less extreme, average daily temperatures were $6.8 \%$ higher in Beltsville, largely due to $11.7 \%$ higher average daily minimum temperatures. Although care was taken in packing and transporting harvested fruit, potential adverse effects of shipping fruit from Ohio to Maryland for firmness instrument evaluations may also have contributed to environmental effects and observed firmness assessments.

Analysis of GCA and SCA effects demonstrated that GCA and SCA were both significant (Table 5). GCA, however, was the principal source of genetic variation. Maryland and Ohio environments were markedly different, and not unexpectedly, GCA $\times$ environment variance was significant for all response variables. SCA $\times$ environment effects were significant only for relaxation curve parameter A. With the exception of 01L652-11, positive GCA effects for compression $\mathrm{F}_{\text {max }}$ were noted for the parental genotypes rated as firm based on subjective handling characteristics (Table 6). The soft-fruited genotypes, plus the firm rated 01L652-11, had negative GCA estimates for compression $\mathrm{F}_{\max }$. Similarly, with the exception of Ohio 8245 produced at both locations and 01L652-11 produced in Ohio, positive GCA effects were noted for fruit puncture resistance (puncture $F_{\max }$ ) in firm 
Table 3. Analysis of variance for the tomato fruit firmness components force at maximum fruit deformation (Compression $\mathrm{F}_{\max }$ ), relaxation curve parameter $\mathrm{A}$, and maximum force required for fruit puncture (Puncture $\mathrm{F}_{\max }$ ).

\begin{tabular}{|c|c|c|c|c|c|c|}
\hline \multirow[b]{2}{*}{ Source } & & $\begin{array}{l}\text { npression } \\
\mathrm{F}_{\max }\end{array}$ & & $\begin{array}{l}\text { elaxation } \\
\text { e parameter } \\
(\times 1000)\end{array}$ & & $\begin{array}{l}\text { uncture } \\
\mathrm{F}_{\max }\end{array}$ \\
\hline & $\overline{\mathrm{df}}$ & $\overline{\text { Mean square }}$ & $\overline{\mathrm{df}}$ & Mean square & $\overline{\mathrm{df}}$ & Mean square \\
\hline Environment & 1 & $789.92^{* * * *}$ & 1 & $2.98^{* * * *}$ & 1 & 3.54 \\
\hline Replicate(environment) & 4 & $15.81^{* * *}$ & 2 & 0.08 & 4 & $2.75^{*}$ \\
\hline Hybrid & 35 & $18.46^{* * *}$ & 35 & $0.08^{* *}$ & 35 & $2.24^{* * *}$ \\
\hline Environment $\times$ hybrid & 35 & $3.07^{*}$ & 35 & 0.06 & 35 & $1.83^{* *}$ \\
\hline
\end{tabular}

${ }^{*, * *, * * *}$ Significant at $P \leq 0.05,0.01$ and 0.001 , respectively.

Table 4. Mean firmness values of hybrids for the tomato fruit firmness components force at maximum fruit deformation (Compression $\mathrm{F}_{\text {max }}$ ), relaxation curve parameter $\mathrm{A}$, and maximum force required for fruit puncture (Puncture $\mathrm{F}_{\max }$ ) in fruit produced at Maryland (MD) and Ohio $(\mathrm{OH})$ test plots.

\begin{tabular}{|c|c|c|c|c|c|c|}
\hline \multirow[b]{2}{*}{ Hybrid $^{\mathrm{z}}$} & \multicolumn{2}{|c|}{$\begin{array}{c}\text { Compression } \mathrm{F}_{\max } \\
{[\text { mean } \pm \mathrm{SE}(\mathrm{N})]}\end{array}$} & \multicolumn{2}{|c|}{$\begin{array}{c}\text { Relaxation curve } \\
\text { parameter A } \\
{[\text { mean } \pm \mathrm{SE}(\times 1000)]}\end{array}$} & \multicolumn{2}{|c|}{$\begin{array}{c}\text { Puncture } F_{\max } \\
{[\text { mean } \pm \mathrm{SE}(\mathrm{N})]}\end{array}$} \\
\hline & MD & $\mathrm{OH}$ & MD & $\mathrm{OH}$ & MD & $\mathrm{OH}$ \\
\hline $1 \times 2$ & $16.95 \pm 1.35$ & $15.66 \pm 1.21$ & $-10.60 \pm 4.90$ & $-5.31 \pm 0.71$ & $15.22 \pm 1.10$ & $14.46 \pm 0.46$ \\
\hline $1 \times 3$ & $21.61 \pm 0.33$ & $16.91 \pm 0.41$ & $-3.08 \pm 0.54$ & $-7.27 \pm 1.46$ & $15.29 \pm 0.84$ & $14.70 \pm 0.75$ \\
\hline $1 \times 4$ & $21.50 \pm 0.38$ & $17.79 \pm 0.69$ & $-25.71 \pm 8.40$ & $-4.35 \pm 1.37$ & $15.77 \pm 0.30$ & $13.31 \pm 0.59$ \\
\hline $1 \times 5$ & $18.33 \pm 0.95$ & $15.12 \pm 1.13$ & $-22.28 \pm 1.54$ & $-5.90 \pm 0.78$ & $13.55 \pm 0.37$ & $14.27 \pm 0.51$ \\
\hline $1 \times 6$ & $18.64 \pm 1.43$ & $14.48 \pm 0.49$ & $-13.00 \pm 5.72$ & $-6.39 \pm 1.38$ & $14.47 \pm 0.49$ & $13.80 \pm 0.42$ \\
\hline $2 \times 3$ & $21.60 \pm 1.23$ & $15.17 \pm 0.48$ & $-18.78 \pm 0.83$ & $-1.94 \pm 2.32$ & $14.50 \pm 0.40$ & $13.67 \pm 0.50$ \\
\hline $2 \times 4$ & $19.59 \pm 0.60$ & $14.64 \pm 0.83$ & $-9.76 \pm 3.28$ & $-4.17 \pm 1.05$ & $14.55 \pm 0.56$ & $14.22 \pm 0.26$ \\
\hline $2 \times 5$ & $16.07 \pm 0.38$ & $14.38 \pm 0.53$ & $-7.86 \pm 2.04$ & $-2.62 \pm 2.73$ & $13.47 \pm 0.51$ & $13.66 \pm 0.37$ \\
\hline $2 \times 6$ & $16.45 \pm 0.72$ & $12.94 \pm 0.50$ & $-11.31 \pm 3.21$ & $-5.97 \pm 2.18$ & $13.81 \pm 0.22$ & $13.61 \pm 0.73$ \\
\hline $3 \times 4$ & $20.44 \pm 0.47$ & $14.88 \pm 0.56$ & $-23.73 \pm 3.38$ & $-10.17 \pm 2.10$ & $14.00 \pm 0.47$ & $14.20 \pm 0.63$ \\
\hline $3 \times 5$ & $19.08 \pm 0.40$ & $14.11 \pm 0.20$ & $-21.36 \pm 4.48$ & $-5.81 \pm 1.97$ & $14.08 \pm 0.17$ & $13.56 \pm 0.53$ \\
\hline $3 \times 6$ & $18.73 \pm 0.93$ & $13.02 \pm 0.30$ & $-29.46 \pm 4.33$ & $-5.84 \pm 1.81$ & $14.56 \pm 0.45$ & $14.54 \pm 0.55$ \\
\hline $4 \times 5$ & $18.51 \pm 1.24$ & $14.72 \pm 0.85$ & $-16.77 \pm 4.34$ & $-6.68 \pm 2.90$ & $13.94 \pm 0.42$ & $13.71 \pm 0.55$ \\
\hline $4 \times 6$ & $18.20 \pm 0.86$ & $13.50 \pm 0.57$ & $-18.96 \pm 0.84$ & $-6.70 \pm 1.51$ & $13.33 \pm 0.47$ & $14.09 \pm 0.51$ \\
\hline $5 \times 6$ & $15.90 \pm 0.41$ & $12.62 \pm 0.78$ & $-16.34 \pm 1.54$ & $-3.01 \pm 1.84$ & $12.85 \pm 0.52$ & $13.72 \pm 0.71$ \\
\hline
\end{tabular}

$\mathrm{z} 1$ = 01L648-8; 2 = 01L652-11; 3 = 02L1370; 4 = Ohio 8245; 5 = 99L115-4; 6 = 00L161-12. Data represents combined reciprocal crosses.

Table 5. Analysis of combining ability for the tomato fruit firmness components force at maximum fruit deformation (Compression $\mathrm{F}_{\max }$ ), relaxation curve parameter $\mathrm{A}$, and maximum force required for fruit puncture (Puncture $\mathrm{F}_{\mathrm{max}}$ ).

\begin{tabular}{lrccc}
\hline & & \multicolumn{3}{c}{$\begin{array}{c}\text { Relaxation } \\
\text { curve parameter } \\
\text { Source }\end{array}$} \\
\hline GCA & df & Compression $\mathrm{F}_{\max }$ & $\mathrm{A}(\times 1000)$ & ${\text { Puncture } \mathrm{F}_{\max }}^{\text {(mean square })}$ \\
SCA & 5 & $91.80^{* * *}$ & $21.88^{* * *}$ & $9.51^{* *}$ \\
GCA $\times$ environment & 15 & $5.48^{* * *}$ & $7.92^{*}$ & 1.17 \\
SCA $\times$ environment & 5 & $7.04^{* *}$ & $5.75^{* *}$ & $5.35^{* *}$ \\
Reciprocal & 15 & 3.11 & $6.94^{*}$ & 1.44 \\
Reciprocal $\times$ environment & 15 & 2.06 & 2.57 & 0.88 \\
Maternal & 15 & 1.54 & 4.39 & 1.05 \\
& 5 & 1.98 & 3.48 & 0.30 \\
\hline
\end{tabular}

${ }^{2}$ GCA (general combining ability); SCA (specific combining ability).

*,**,***Significant at $P \leq 0.05,0.01$, and 0.001 , respectively. 
Table 6. Estimates of individual general combining ability effects for the tomato fruit firmness components force at maximum fruit deformation $\left(\right.$ Compression $\mathrm{F}_{\max }$ ), relaxation curve parameter $\mathrm{A}$, and maximum force required for fruit puncture (Puncture $\mathrm{F}_{\max }$ ) in fruit produced at Maryland $(\mathrm{MD})$ and Ohio $(\mathrm{OH})$ test plots.

\begin{tabular}{|c|c|c|c|c|c|c|c|c|c|c|c|c|}
\hline \multirow[b]{3}{*}{ Source } & \multicolumn{4}{|c|}{ Compression $\mathrm{F}_{\max }(\mathrm{N})$} & \multicolumn{4}{|c|}{ Relaxation curve parameter A $(\times 1000)$} & \multicolumn{4}{|c|}{ Puncture $\mathrm{F}_{\max }(\mathrm{N})$} \\
\hline & \multicolumn{2}{|c|}{ MD } & \multicolumn{2}{|c|}{$\mathrm{OH}$} & \multicolumn{2}{|c|}{ MD } & \multicolumn{2}{|c|}{$\mathrm{OH}$} & \multicolumn{2}{|c|}{ MD } & \multicolumn{2}{|c|}{$\mathrm{OH}$} \\
\hline & Estimate & $P^{z}$ & Estimate & $P$ & Estimate & $P$ & Estimate & $P$ & Estimate & $P$ & Estimate & $P$ \\
\hline 01L648-8 & 0.88 & 0.0023 & 1.50 & $<0.0001$ & 3.71 & 0.0177 & 3.53 & 0.0951 & 0.98 & $<0.0001$ & 0.11 & 0.5058 \\
\hline 01L652-11 & -0.82 & 0.0039 & -0.32 & 0.0535 & 4.45 & 0.0048 & -4.33 & 0.8383 & 0.21 & 0.1331 & -0.12 & 0.4480 \\
\hline 02L1370 & 1.84 & $<0.0001$ & 0.82 & $<0.0001$ & -4.93 & 0.0049 & -9.71 & 0.6631 & 0.24 & 0.0769 & 0.06 & 0.7212 \\
\hline Ohio 8245 & 0.81 & 0.0049 & 0.33 & 0.0469 & -2.24 & 0.1415 & -7.76 & 0.7185 & -0.08 & 0.5620 & -0.46 & 0.7687 \\
\hline 99L115-4 & -1.39 & $<0.0001$ & -0.85 & $<0.0001$ & -1.32 & 0.3655 & -4.03 & 0.8522 & -0.77 & $<0.0001$ & -0.06 & 0.7224 \\
\hline 00L161-12 & -1.31 & $<0.0001$ & -1.48 & $<0.0001$ & 0.33 & 0.8184 & -9.46 & 0.6998 & -0.58 & $<0.0001$ & -0.18 & 0.2588 \\
\hline
\end{tabular}

$\bar{z}(P>t)$.

parents and negative GCA estimates were obtained for soft-fruited parental genotypes. Puncture $\mathrm{F}_{\max }$ estimates were non-significant for genotypes 01L652-11 and Ohio 8245. Genotypes 01L648-8 and 02L1370 were unique in combining positive GCA effects for both compression and puncture resistance. Reciprocal and maternal effects were not significant for the firmness attributes evaluated.

The GCA estimates for compression $\mathrm{F}_{\max }$, relaxation curve parameter $\mathrm{A}$, and puncture $\mathrm{F}_{\text {max }}$ were generally consistent with firmness attribute scores previously noted wherein the parental genotypes exerted corresponding positive or negative effects on hybrid progeny (Table 4, Fig. 2). In other words, there was some degree of correlation between a genotype's performance as an inbred and its GCA. GCA can be interpreted in terms of additive genetic variance (Griffing, 1956). Thus, breeding methods that exploit additive variation would be most appropriate for increasing firmness, as assessed by compression and puncture resistance, in these materials. Significant, albeit small deviation, from the average GCA of parental genotypes (i.e., the SCA of the cross) was evident for all response variables indicating that there may be some exploitable non-additive variation. In agreement with the combining ability analysis, narrow-sense heritability estimates across environments for compression $\mathrm{F}_{\max } \pm \mathrm{SE}$ and puncture $\mathrm{F}_{\max } \pm \mathrm{SE}$ were relatively high, $0.94 \pm 0.04$ and $0.88 \pm$ 0.003 , respectively. Again, additive variance for the fruit firmness attributes was high.

Our results demonstrate that there is genetic variation in fruit firmness of the selected tomato genotypes that could be exploited in a breeding program to improve firmness. The results also demonstrate that different attributes may contribute to fruit firmness and that multiple measurement modes may be necessary to adequately detect firmness differences. Our results provide indirect evidence that $L$. cheesmanii may contribute additive genetic variance for improvement of tomato fruit firmness, thus potentially broadening the genetic base for fruit firmness. The pedigrees of the parental genotypes; variation detected in compression, relaxation, and force to puncture parameters; and the different GCA effects suggest that examining progeny of 01L648-8 X Ohio 8245 or 01L648-8 X 02L1370 will lead to the identification of superior lines as firmness appears to be derived from different sources.

Additional studies are required to identify these quantitative trait loci (QTL) and confirm their origin. Despite inferior phenotypes of wild species, including the L. cheesmanii accession utilized to develop a number of the breeding lines in the current study, these species contain QTLs that can substantially increase tomato fruit quality. In a number of studies, $10 \%$ to $50 \%$ of the
QTLs detected in wild species were ones that had a positive effect on the trait of interest, despite the fact that the wild species phenotype was inferior to that of the cultivated parent (e.g., de Vicente and Tanksley 1993; Eshed and Zamir 1994; Kabelka et al., 2004). Using advanced backcross QTL analysis of near-isogenic lines with introgressions from $L$. hirsutum Dunal and $L$. pimpinellifolium, QTLs that significantly improved fruit firmness were identified (Bernacchi et al., 1998). These studies and others illustrate the potential for utilization of wild species to broaden the genetic base of fruit firmness and improve fruit quality. The line 01L648-8 will be a valuable resource for identifying $L$. cheesmanii alleles that contribute to firmness when introgressed into cultivated genetic backgrounds.

\section{Literature Cited}

Al-Falluyi, R.A., D.H. Trinklein, and V.N. Lambeth. 1982. Inheritance of pericarp firmness in tomato by generation means analysis. HortScience 17:763-764.

Aly, M.A.A.,A.S. Beltagy, and G.E. Hobson. 1986. Comparison between three tomato lines (Rin Rin, Rin rin, and rin rin) in ACC content, loss in firmness and loss in weight. Acta Hort. 190:183-190.

Bernacchi, D., T. Beck-Bunn, D. Emmatty, Y. Eshed, S. Inai, J. Lopez, V. Petiard, H. Sayama, J. Uhlig, D. Zamir, and S. Tanksley. 1998. Advanced backcross QTL analysis of tomato. II. Evaluation of near-isogenic lines carrying single-donor introgressions for desirable wild QTL-alleles derived from Lycopersicon hirsutum and L. pimpinellifolium. Theor. Appl. Genet. 97:170-180.

Berry, S.Z. and W.A. Gould. 1991. 'Ohio 8245 ' processing tomato. HortScience 26:1093.

Cosgrove, D.J. 2000. Loosening of plant cell walls by expansins. Nature 407:321-326.

de Vicente, M.C. and S.D. Tanksley. 1993. QTL analysis of transgressive segregation in an interspecific tomato cross. Genetics 134:585-596.

Elkind, Y., A. Cahaner, and N. Kedar. 1990. A mixed model for the effects of single gene, polygenes, and their interaction on quantitative traits. 2. The effects of the nor gene and polygenes on tomato fruit softness. Heredity 64:205-213.

El-Sayed, M., N.K. Mohamed, and H.T. Erickson. 1966. Inheritance of tomato fruit firmness. J. Amer. Soc. Hort. Sci. 89:523-527.

Eshed, Y. and D. Zamir. 1994. Introgressions from Lycopersicon pennellii can improve the soluble solids yield of tomato hybrids. Theor. Appl. Genet. 88:891-897.

Griffing, B.A. 1956. Concept of general and specific combining ability in relation to diallel crossing systems. Austr. J. Biol. Sci. 9:463-493.

Hallauer, A.R. and J.B. Miranda. 1981. Quantitative genetics in maize breeding. Iowa State Univ. Press, Ames.

Kabelka, E., W. Yang, and D.M. Francis. 2004. Improved tomato fruit color within an inbred backcross line derived from Lycopersicon esculentum and L. hirsutum involves the interaction of loci. J. Amer. Soc. Hort. Sci. 129:250-257. 
Kamimura, S., H. Yoshikawa, and K. Ito. 1973. Breeding studies for fruit firmness in tomatoes. Bul. Hort. Res. Sta. (Min. Agr. For.) Ser. C (Morioka) 8:13-26.

Kramer, M. R. Sanders, H. Bolkan, C. Waters, R.E. Sheehy, and R.W. Hiatt. 1992. Postharvest evaluation of transgenic tomatoes with reduced levels of polygalacturonase: Processing firmness and disease resistance. Postharvest Biol. Technol. 1:241-245.

Kuehn, M. E. and C. Nichols. 2003. Inbred tomato line 294. U.S. Patent Application, 20030126649. U.S. Patent and Trademark Office, Washington, D.C.

Precheur, R.J. 2000. Ohio vegetable production guide. The Ohio State Univ. Coop. Ext., Bul. 672.

Rau, G.A., C.E. McCulloch, and M.A. Mutschler. 1994. Evaluation of parental-type classification for the inbred-backcross method of estimating gene number. J. Hered. 85:105-111.

Schuch, W. 1994. Improving tomato quality through biotechnology. Food Tech. 78-83.

Scott, J.W. 1983. Genetic sources of tomato firmness. Proc. Fourth
Tomato Quality Workshop, Miami, Fla., 7-10 Mar. 1983. Vegetable Crops Research Rpt., VEC-83-1, p. 60-67.

Smith, D.L., J.A. Abbott, and K.C. Gross. 2002. Down-regulation of tomato $\beta$-galactosidase 4 results in decreased fruit softening. Plant Physiol. 129:1755-1762.

Stevens, M.A. 1986. Inheritance of tomato fruit quality components. Plant Breeding Rev. 4:273-311.

Stevens, M.A. and C.M. Rick. 1986. Genetics and breeding. p. 35-109. In: J.G. Atherton and J. Rudich (eds.). The tomato crop-A scientific basis for improvement. Chapman and Hall, New York.

University of Maryland. 2000. Commercial vegetable production recommendations. Univ. Maryland Coop. Ext. Serv. Bul. 236, College Park.

$\mathrm{Wu}, \mathrm{T}$. and J.A. Abbott. 2002. Firmness and force relaxation characteristics of tomatoes stored intact or as slices. Postharvest Biol. Technol. 24:59-68.

Zhang, Y. and M.S. Kang. 1997. DIALLEL-SAS: A SAS program for Griffing's diallel analyses. Agron. J. 89:176-182. 